\title{
TRICHINELLOSIS IN GREECE: A REVIEW
}

SOTIRAKI S.T.*, ATHANASIOU L.V.**, HIMONAS C.A.*, KONTOS V.J.** \& KYRIOPOULOS I.**

\section{Summary :}

Trichinellosis which constitutes a public health problem in many countries seems to be of no importance on both pig industry and public health in Greece, where in spite of a law requiring mandatory use of trichinoscopy during meat inspection, muscle larvae have not been found in slaughtered pigs since 1957 in Thessaloniki and 1967 in Athens. Since its first recovery in 1946 and up to 1952, human trichinellosis has been found or suspected in 22 persons in the area of Athens and Thessaloniki. Moreover, in 1968, T. spiralis larvae were found incidentally in a human with laryngeal tumor and in 1971, living larvae were postmortem recovered in the diaphragm of a 70 -year-old man. The average incidence of infection in pigs at that time was 0.02-2.2\%. Since then, no other clinical case had been reported up to 1982 1984 when 15 people were found to harbor the parasite and fourteen of them were part of an outbreak which occurred in a small village in Northern Greece. Moreover, $1.07 \%$ of the pig serum samples which came from the same area, showed the presence of specific antibodies. Because of the above data, it is generally accepted that in Greece $T$. spiralis is only rarely spread in man.

KEY WORDS : trichinellosis, human, Greece.

S ince the larvae were discovered from human muscle in England in 1835, Trichinella is recognized to exist in most of the northern hemisphere, including the Arctic, and parts of Africa, South America and Asia (Parasitic Zoonoses. W.H.O. Report, 1979). In Europe the morbidity rate was declined in recent decades, both in western and eastern countries (Acha \& Szyfres, 1989) but in most eastern European countries there is a remarkable increase of trichinellosis in animal and man from the beginning of 90 ties. The sporadic cases reported in western European countries recently resulted mostly from consumption of horse meat (i.e. in France; Ancelle et al., 1988, Ancelle et al., 1998 and in Italy, Pozio et al., 1988) or wild animals (i.e. wild boar in Italy; Di Bari et al., 1990; Frongillo et al., 1992; and in Spain, Rodriguez-Osorio et al.; 1990, Rodriguez-Osorio et al., 1999). Accor-

\footnotetext{
* Laboratory of Parasitology, Faculty of Veterinary Medicine, Aristotle University, 54006 Thessaloniki, Greece.

** National School of Public Health, Alexandra's avn. 196, 11521, Athens, Greece.

Correspondence: Dr Smaro Sotiraki.

Fax : +30 31999947 - Tel.: +30 31999939.

E-mail : sotiraki@vet.auth.gr
}

dingly, in many European countries this parasitosis is no longer found in swine; the highest frequency encountered is about $0.1 \%$ usually on small farms (Acha \& Szyfres, 1989). However, use of digestion method demonstrated that some pigs had very low intensity infections with 0.025 larvae per gram of meat (Ruitenberg et al., 1983).

As far as Greece concerns the parasite was firstly recovered in humans in 1946, regarded to a six persons outbreak (Livieratos et al., 1948) and up to 1,952 human trichinellosis has been found or suspected in 22 persons in central Greece (Papadakis, 1956) and in another one in northern Greece (Panagiotopoulos \& Valtis, 1951; in Himonas, 1971). It was then assumed theoretically, since no epidemiological survey was carried out, that in Greece, one case of trichinellosis occurred every year (Merle, 1957). The average incidence of infection in pigs at that time was $0.02-2.2 \%$, a fact that classified Greece among the most frequently infected countries in Europe at that time such as Poland and Romania where rates of infection ranged from 0.02 to $0.06 \%$ (Euzeby, 1964). More precisely, in Athens, from 1952 to 1953 a total of 15,704 slaughtered pigs was examined and the incidence of infection was found to be $0.74 \%$ (Kinnas \& Karamarias, 1953), and in Thessaloniki, from 1952 to 1958 from a total of 57,165 slaughtered pigs the incidence of infection was $0.12 \%$ (Smokovitis, 1970).

Later on, in spite of the law requiring mandatory use of trichinoscopy during meat inspection in Greece, muscle larvae have not been found in slaughtered pigs excepting one single case in 1967 in Athens, where 23 out of 1,034 (2.2\%) pigs were Trichinella-positive. These animals were slaughtered because of a foot and mouth disease outbreak (Smokovitis, 1970). However, concerning man, T. spiralis larvae were found incidentally in 1968, during the microscopic examination of a human with laryngeal tumor (Chantzos, 1968, in Himonas, 1971). In 1971, live T. spiralis larvae were recovered from the diaphragm of a 70 -year-old man, during a post-mortem survey including artificial digestion of 154 human diaphragms taken from dead bodies autopsied in the Medical Jurisprudence Laboratory of 
Thessaloniki, Greece (Himonas, 1971). The above findings showed an incidence of $0.65 \%$, which although did not represent the real one, due to the limited number of samples, indicated that the parasite infection existed.

Since then, no other clinical case had been reported up to 1982-1984, when 15 people were found to be infected by Trichinella in the area of Central and Northern Greece. Fourteen of them belonged to an outbreak, which occurred in a small village of Chalkidiki province in Macedonia. All of them were members of three relative families and all these people consumed meat and/or sausages prepared from one free grazing pig. The disease was suspected from its clinical features and was diagnosed serologically (i.e. ELISA plus C-ELISA). Encysted larvae were also found in a deltoid muscle biopsy sample (Vouyoukas et al., 1982). Moreover, in 1987 as a result of a survey in which 372 pigs were examined serologically, $1.07 \%$ of the pig sera samples, showed the presence of specific antibodies. All sera were collected from the same outbreak area (Haralabidis \& Himonas, 1987). The other case was referring to a young man infected by eating a home-made sausage. Beside the patient, larvae were also detected in the sausage (Haralabidis, 1984). On top of these, Trichinella infection in Greece has been reported in gray rats $(0-60 \%)$, foxes, wolves, dogs (4\%) and horses (1.4\%) (Himonas, 1971, Alexakis, 1978, Haralabidis et al., 1993).

In conclusion, comparing the absence of any recent Trichinella cases in humans with the remarkable increase of pork production and consumption in Greece during the last years (average of slaughtered pigs/year: $2,500,000$ ), it seems that trichinoscopy used in the inspection of pork, has been shown to be effective, even if this is in opposition with the latest scientific report of $\mathrm{EU}$, in protecting the population. At the same time, trichinoscopy presents serious limitations because of its low sensitivity. Experts estimate that this method can detect infection when there are three or more larvae per gram of muscle; according to others, the sensitivity is 10 larvae per gram (Acha \& Szyfres, 1989). It also requires special equipment and expertise and is costly and time consuming (Kolata, 1985). Although the technique leaves much to be desired, and international efforts has been undertaken to replace trichinoscopy by more accurate methods, when correctly executed it protects the consumer against massive infections. Nevertheless, every case is important at individual level and that is exactly why surveillance is required to eliminate the risk of human infections especially since the low sensitivity of trichinoscopy could be probably misleading about the parasite's reservoir in pigs. At the individual level, and to avoid occurrence of such outbreaks described, humans should abstain from eating raw pork or pork products derived from animals that may not have been subjected to veterinary inspection. In any case, such products can be submitted to several processes to destroy the trichinae such as cooking, freezing, or any other methods of killing the larvae (Acha \& Szyfres, 1989).

\section{REFERENCES}

Acha P.N. \& Szyrres B. Zoonoses and Communicable Diseases common to man and animals. $2^{\text {nd }}$ edition, Pan American Health Organization, 1989 Washington DC, USA, 820-834.

AlEXAKIs A. Epizootiological notes on trichinosis. A survey in stray dogs (Canis familiaris). Helliniki Iatriki, 1978, 47, 415-416.

Ancelle T., Dupouy-Camet J., Bougnoux M.E., Fourestie V., Petiti H., Mougeot G., Nozais J.P. \& Lapiere J. Two outbreaks of trichinosis caused by horsemeat in France in 1985. American Journal of Epidemiology, 1988, 127 (6), 1302-10311.

Ancelle T., Dupouy-Camet J., Desenclos J.C., Maillot E., Savage-Houze S., Charlet F., Drucker J. \& Moren A. A multifocal outbreak of trichinellosis linked to horsemeat imported from North America to France in 1993. American Journal of Tropical Medicine and Hygiene, 1998, 59 (4), 615-619.

Di Bari C., Santagada G., Pozio E. \& Schiradi O. Epidemiological research on trichinellosis in Apulia and Basilicata (southern Italy). European Journal of Epidemiology, 1990, 6 (4), 412-415.

Euzeby J. Les Zoonoses Helminthiques. Vigot Fr (ed) Paris, France, 1964, 389.

Frongillo R.F., Baldelli B., Pozio E., Crapa G., Di Giuli C., SANTIROCCHI M. \& Di LeONARdo F. Report on an outbreak of trichinellosis in Central Italy. European Journal of Epidemiology, 1992, 8(2), 283-288.

HARALABIDIS S.T. Application of CELISA to the parasitic infections. III Detection of complement fixing Trichinella spiralis antibodies. Hellenic Armed Forses Medical Review, 1984, 18, 197-201.

Haralabidis S.T. \& Himonas C.A. Detection of trichinellosisimmunoglobulins. Acta Microbiologica Hellenica, 1987, 32, 21-30.

Haralabidis S., Himonas C. \& Simos E. Detection of IgG T. spiralis in the horse. Bulletin of the Hellenic Veterinary Medical Society, 1993, 44 (2), 104-106.

Himonas C.A. The present status of human trichinosis in Greece. Journal of Parasitology, 1971, 57, 1368-1369.

KinNAS C. \& KaRAMARIAS D. Trichinosis, edited by the authors, Athens Greece, 1953, 206.

Kolata G., Testing for Trichinosis. Science, 1985, 227, 621624.

Livieratos S., Danopoulos E. \& Logothetopoulos I. The first outbreak of trichinellosis in Greece : Study of the disease. Helliniki Iatriki, 1946, 17 (8), 681-710. 
Merle. P. Bulletin de l'Office International des Epizooties, 1957, Paris France.

PAPADAKIS A. Treatise of Parasitology. Rodis Br. (ed), Athens Greece, 1956, 924.

Parasitic Zoonoses. Report of a WHO Expert Committee, 1979 W.H.O., Geneva.

Pozio E., Cappelli O., Marchesi L., Valeri P. \& Rossi P. Third outbreak of trichinellosis caused by consumption of horsemeat in Italy. Annales de Parasitologie Humaine et Comparée, 1988, 63 (1), 48-53.

Rodriguez-Osorio M., Gomez-Garcia V., Rodriguez-Perez J. \& Gomez-Morales M.A. Seroepidemiological studies on five outbreaks of trichinellosis in southern Spain. Annals of Tropical Medicine and Parasitology, 1990, 84 (2), 181-184.

Rodriguez-Osorio M., ABD J.M., DE Haro T., Villa-Real R. \& Gomez-GaRcia V. Human trichinellosis in Southern Spain: serologic and epidemiologic study. American Journal of Tropical Medicine and Hygiene, 1999, 61 (5), 834-837.

Ruttenberg E.J, VAn Krapen F. \& Elgersma A. Incidence and control of Trichinella spiralis thoughout the world. Food Technology, 1983, 37, 98-100.

SMокоviтis A. Epizootiological studies of the farm animals diseases in Greece and especially in the District of Thessaloniki, edited by the author, Thessaloniki, Greece, 1970, 652.

Vouyoukas A., Kavaliotis J., Haralabidis S., Hatzibouyas J., Vliakoftis I., Manes C., Bandios S., Kalligatsis C., PapaChristou A., Manios S. \& Himonas C. An outbreak of trichinellosis in Chalkidiki, Northern Greece. Helliniki Iatriki, 1982, 48, 343-348. 